\title{
Climate change, human health and the role of environmental health practitioners
}

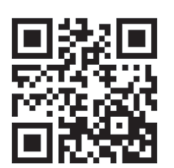

There is advanced consensus on the anthropogenic roots of climate change. ${ }^{[1,2]}$ Extreme weather events, including storms of increased intensity or frequency, heatwaves, floods and droughts, as well as rising sea levels and crop failure, are among the most significant associated environmental and public health challenges. ${ }^{[3,4]}$ Such climate and environmental changes place at risk the fundamental human resources for health, such as shelter, clean water, air quality, and food security and quality. Environmental health practitioners (EHPs) have for decades played a critical role in monitoring and controlling the quality and health of the human environment. They now have an equally important role to play with regard to adaptation strategies and measures to protect communities against the challenges of climate variability at a grassroots level.

\section{Climate change impacts on human health}

The natural 'greenhouse effect' is necessary to maintain a constant, habitable temperature on Earth. However, in recent decades increased emissions of greenhouse gases such as carbon dioxide and methane from anthropogenic activities have intensified this effect, leading to a general warming of ambient temperatures at the earth's surface, changing rainfall patterns and distribution, altering cloud cover and raising the incidence of extreme weather events.

Projections from climate models used to predict these changes suggest a warming in temperature for southern Africa greater than the global average. ${ }^{[5-7]}$ Regional measurements of temperature in recent decades show that annual maximum and minimum temperatures have been increasing, and moreover that the rate of increase is increasing and that this impact is projected to continue into the future. ${ }^{[8]}$ This has potentially significant implications for quality of life and human health. The direct effects of increased temperature include nausea, headaches, elevated levels of kidney and cardiovascular disease, heatstroke and even death. Indirectly, air quality may be affected by changing the type of chemical pollutants as well as the distribution and quantity of pollens and other allergens, ${ }^{[4,9]}$ leading to detrimental impacts on respiratory health and aggravation of conditions such as asthma and allergic rhinitis. Increased temperatures may also enhance evaporation and other water cycle processes and lead to a reduction in water availability, reduced water quality and increases in waterborne diseases. There may also be general disruption of agriculture, with concomitant food security risks, displacement of people, and increases in vector- and rodent-borne diseases.

The magnitude of the impact that warming has already had on the health of South Africans is not well understood, and the potential risk to health from future climate change has not been quantified. However, there is a strong consensus that the region will experience negative health impacts from a changing climate. Additionally, as stated in the most recent Fifth Assessment Report of the Intergovernmental Panel on Climate Change (AR5), ${ }^{[4]}$ the largest health risks resulting from a changing climate will be in those communities and populations currently most impacted on by climate-related diseases. There is therefore a particular need for local on-the-ground action and planning to understand current impacts, decrease vulnerability and mitigate the health impacts of climate change.

\section{Environmental health and EHPs}

The advent of climate change compels all in the public and environmental health field to reassess the environmental health risks that communities currently face, and decide on the optimal responses going forward. The overall goal of environmental health is to prevent disease through the control of environmental factors that may impact on an individual's health and wellbeing, and by promoting the creation of health-supportive environments. ${ }^{[10]}$ EHPs are the professionals tasked to implement environmental health services and protect communities from environmental pollution and related harmful effects. In this regard, their broad-based training, skills and expertise, as well as their regulatory powers and location at the environment-public health nexus, make them ideally suited to make an important contribution with regard to adaptation at the local level. ${ }^{[1]]}$ In the course of their daily work, EHPs assess environmental health risks, provide information to the public, plan and implement a range of programmes and projects, and create partnerships among, for example, communities, health services, energy providers, housing departments and the private sector.

Intergovernmental Panel on Climate Change AR5 emphasises the need for effective adaptation measures in the health sector for the near term, such as the provision of clean water and sanitation, increased capacity for disaster preparedness and response, improved surveillance and early warning systems and climate change vulnerability mapping. ${ }^{[4]}$ Given their close interactions with communities, EHPs are well placed to play a central and strong role.

While climate and health adaptation has been considered at national level in South Africa (SA) through, for example, the drafting of a National Climate and Health Adaptation Plan, similar initiatives pertaining to climate change and health, and the shaping of roles for local-level EHPs, are still at an early stage at the all-important local level. Health activities and functions that might be considered for EHPs include: ${ }^{[12]}$

- becoming change agents and facilitating adaptive action across sectors

- working with individuals, groups, organisations and communities to build capacity and to embrace innovation and creative solutions to climate problems

- developing programmes and campaigns to increase awareness of climate and health concerns at community level, especially in high-risk areas (such as cities) and high-risk groups (impoverished communities and groups such as the elderly, the very young, those with pre-existing ill health conditions and those living alone)

- initiating or supporting community-based mitigation measures (that may also have health co-benefits), such as facilitating the infrastructure for, and encouraging, walking and cycling, carpooling, green buildings and community greening programmes

- strengthening research programmes, and monitoring and surveillance systems to include climate and weather measurements and related ill-health outcomes

- considering climate change and greenhouse gas emissions when requested to comment on development proposals

- promoting strengthening of planning and development policies (for example, in establishment of flood lines and building standards)

- advocating for climate-friendly policies across sectors

- ensuring that disaster management and outbreak response plans are in place

- facilitating communication of signals from early warning systems. 
In shaping the roles of EHPs in relation to climate and health adaptation in SA, and making decisions on resource allocation, a range of social factors that affect people's vulnerability and resistance to a changing climate will also need to be taken into account. For example, poverty, inequality and hazardous living environments increase vulnerability to weather extremes (i.e. heatwaves, floods, droughts, etc.), food insecurity and declining food quality, and altered disease distributions. In Limpopo Province, for example, where only $18 \%$ of households have access to an indoor water supply and $22 \%$ access to a flush toilet, and only half of all households use electricity for daily cooking, ${ }^{[13]}$ the effects of climate change may be expected to exacerbate the high degree of existing environmental health vulnerability.

\section{The time is now}

Dissidence regarding the reality of climate change has diminished, and the debate has shifted to the magnitude of the challenge ahead ${ }^{[11]}$ and the practical adaptation and coping mechanisms needed at all levels. The time to act is now, and EHPs, at the interface between environment and health, have a crucial role to play. To fulfil their potential, the environmental health profession needs to spearhead discussions

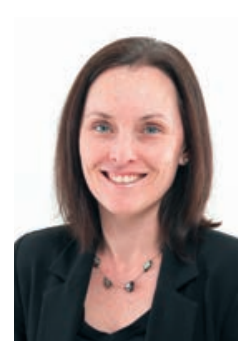
regarding critical climate impacts on health and wellbeing and become the stewards of health adaptation measures at the local level.

\section{Caradee Y Wright}

CSIR Climate Studies, Modelling and Environmental Health Research Group, Pretoria, and School of Geography, Geoinformatics and Meteorology University of Pretoria, South Africa cwright@csir.co.za

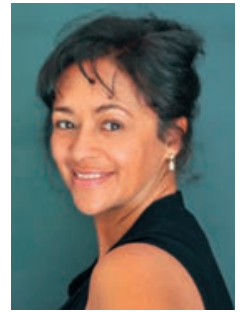

\section{Angela Mathee}

Environment and Health Research Unit, South African Medical Research Council, Johannesburg, South Africa, Faculty of Health Sciences, University of Johannesburg, and School of Public Health, University of the Witwatersrand, Johannesburg

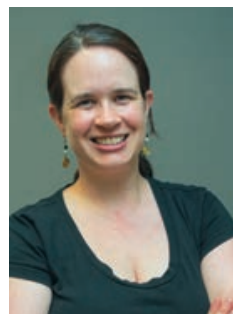

\section{Rebecca M Garland}

CSIR Climate Studies, Modelling and Environmental Health Research Group, Pretoria, South Africa, and Climatology Research Group, Unit for Environmental Sciences and Management, North West University, Potchefstroom, South Africa

1. Hegerl GC, Zwiers FW, Braconnot P, et al. Understanding and attributing climate change. In: Solomon S, Qin D, Manning M, et al., eds. Climate Change 2007: The Physical Science Basis. Contribution of Working Group I to the Fourth Assessment Report of the Intergovernmental Panel on Climate Change. Cambridge Cambridge University Press, 2007:665-745. https://www.ipcc.ch/pdf/assessment-report/ar4/wg1/ar4-wglchapter9.pdf (accessed 30 June 2014)

2. McMichael AJ, Woodruff RE, Hales S. Climate change and human health: Present and future risks. Lancet 2006;367(9513):859-869. [http://dx.doi.org/10.1016/s0140-6736(06)68079-3]

3. World Health Organization. Protecting Health from Climate Change: Global Research Priorities. Geneva WHO, 2009. http://www.who.int/globalchange/publications/reports/9789241598880/en/ (accessed 27 January 2014).

4. Smith KR, Woodward A, Campbell-Lendrum D, et al. Human health: Impacts, adaptation and co-benefits In: Field CB, Barros V, Dokken D], et al., eds. Impacts, Adaptation and Vulnerability. Contribution o Working Group II to the Fifth Assessment Report of the Intergovernmental Panel on Climate Change. Cambridge: Cambridge University Press, 2014:1-69. http://ipcc-wg2.gov/AR5/images/uploads/WGIIAR5Chap11_FGDall.pdf (accessed 30 June 2014).

5. Christensen JH, Hewitson B, Busuioc A, et al. Regional climate projections. In: Solomon S, Qin D, Manning M, et al., eds. Climate Change 2007: The Physical Science Basis. Contribution of Working Group I to the Fourth Assessment Report of the Intergovernmental Panel on Climate Change. Cambridge: Cambridge University Press, 2007:847-940. https://www.ipcc.ch/pdf/assessment-report/ar4/../ar4-wg1-chapter11.pdf (accessed 1 July 2014)

6. Engelbrecht FA, McGregor JL, Engelbrecht CJ. Dynamics of the conformal-cubic atmospheric model projected climate-change signal over southern Africa. International Journal of Climatology 2009;29(7):10131033. [http://dx.doi.org/10.1002/joc.1742]

7. Niang I, Ruppel OC, Abdrabo M, et al. Africa. In: Field C, Barros V, eds. Impacts, Adaptation and Vulnerability. Contribution of Working Group II to the Fifth Assessment Report of the Intergovernmental Panel on Climate Change. Cambridge: Cambridge University Press, 2014:1-114. http://ipcc-wg2.gov/AR5 images/uploads/WGIIAR5-Chap22_FGDall.pdf (accessed 30 June 2014).

8. South African Risk and Vulnerability Atlas. 2013. http://www.sarva.org.za/sadc/download/sadc_handbook pdf (accessed 27 January 2014).

9. Confalonieri UB, Menne R, Akhtar KL, et al. Human health. In: Parry ML, Canziani OF, Palutikof JP, et al, eds. Climate Change 2007: Impacts, Adaptation and Vulnerability. Contribution of Working Group II to the Fourth Assessment Report of the Intergovernmental Panel on Climate Change. Cambridge: Cambridge University Press, 2007:391-431. http://www.ipcc.ch/publications_and_data/ar4/wg2/en/ch8.html (accesse 1 July 2014).

10. World Health Organization. Promoting Physical Activity and Active Living in Urban Environments Geneva: WHO, 2006. http://www.euro.who.int/_data/assets/pdf_file/0009/98424/E89498.pdf (accessed

11. Schwartz BS, Parker C, Glass TA, Hu H. Global environmental change: What can health care providers and the environmental health community do about it now? Environ Health Perspect 2006;114(12):1807-1812. [http://dx.doi.org/10.1289/ehp.9313]

2. Losito D, Noble D. Climate change and the role of Canada's environmental health professionals Environmental Health Review 2007:Spring:20-23. http://www.2degreesc.com/Files/Climate\%20change\%20 and\%20the\%20role\%20 of\%20 Canadås\%20EPHs.\%20EHR_Spring07.pdf (accessed 27 January 2014).

13. Statistics South Africa. Census in Brief: 2011. Pretoria: Statistics South Africa, 2012. http://www.statssa.gov za/census2011/Products/Census_2011_Census_in_brief.pdf (accessed 27 January 2014).

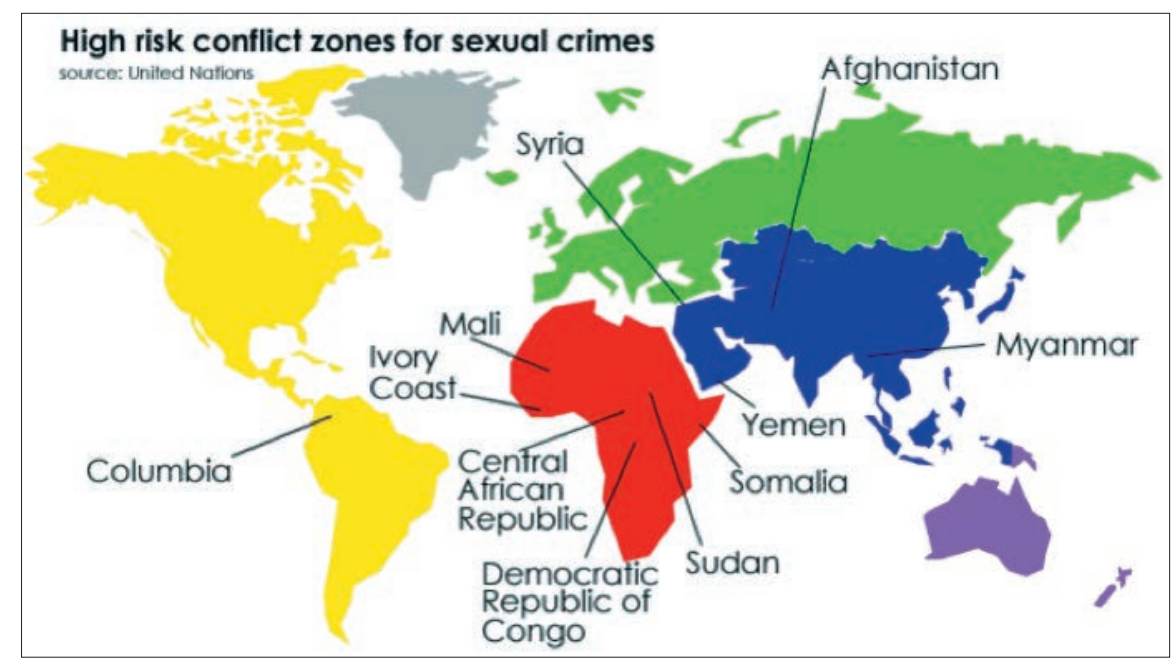

Where is sexual violence happening in conflict zones? ${ }^{\text {[4] }}$ (See p. 517.) 